magnets, would cost "1.5 LEP").

In any case, physicists would prefer to see what LEP itself produces before linking their ambitions to a particular successor. Some choices, the possibility of building opposed electron and positron colliders, for example, might make it necessary to leave the cramped site at Geneva.

On the face of things, CERN can thus see the way forward until the end of the century, which will amount to roughly half a century after its foundation (at a meeting organized by UNESCO in 1951). What, by then will it have accomplished?

Judgements of this kind are necessarily subjective. From the start, CERN has been most notably a European citadel of technical expertise, both in the construction of scientific instruments on a huge scale and in the development of fast data networks and communications interfaces for the handling of the data it produces.

While there is a sense in which CERN would be a pale shadow of its present self had it not been for the discovery of the $\mathrm{Z}^{0}$ and the $\mathrm{W}^{ \pm}$mesons, that slights the importance of the growing range of general physics that pours out of Geneva each year, from the precise determination of the gyromagnetic ratio to the fabrication of atoms of antimatter.

Luck has helped. At the outset, with nuclear physics riding high and not easily distinguished from high-energy physics, CERN enjoyed the enthusiastic backing of powerful figures in Britain, France, West Germany and Italy. But by being consistently more cosmopolitan than its membership (with deliberate policies of forging links with Soviet and US physics), it has won and kept a place in international high-energy physics. In the process, it has become a free-standing centre of excellence whose connections run through the whole of Europe. There are many projects on which Europe spends 800 million francs a year without anything like the benefit.

\title{
CARLO RUBBIA
}

\section{New machinery on the horizon?}

\section{Geneva}

CARlo Rubbia is a tall man with a stoop who became director of CERN at the beginning of the year, after helping to put the institution on the map by finding the intermediate heavy bosons (and being awarded the Nobel prize for physics in 1987). He seems to have thrown himself into his new job with high-energy diplomacy, talking to the high-energy physics communities elsewhere, notably in the United States.

Rubbia is in no doubt that CERN is technically more excellent at the craft of building particle accelerators than either the United States or the Soviet Union. He points to the high estimated cost of building the SCSC in Texas, probably in excess of $\$ 4,500$ million, and to the difficulties (now resolved) of grafting onto the Stanford Linear Accelerator a device for colliding electrons at high energy.

But Rubbia also acknowledges that accelerators cannot keep on growing as they have been, and that the time must come when accelerators are built in a wider framework than in the past. Whence the diplomacy.

The strategy is to keep CERN in the forefront of high-energy physics while arranging that member states in Europe do not have to meet all the extra cost. Rubbia claims that Geneva has the world's only permanent team of accelerator designers and builders whose success has been established by demonstration. Will not others wish to join in collaborations with them, not just for physics but for construction?

One intriguing possibility is that future members in large consortia might make contributions in kind to future projects. There is even talk that the Soviet highenergy physics laboratory at Serpukhov,

which is already fabricating superconducting magnets for its own new proton accelerator, might carry on making magnets for the Large Hadron Collider at CERN when its own needs have been met. Rubbia will make partnerships with anybody, on any favourable terms, to see the next generation under way.

But what would happen CERN if good sense required that the next machine should be built, perhaps by a larger consor-

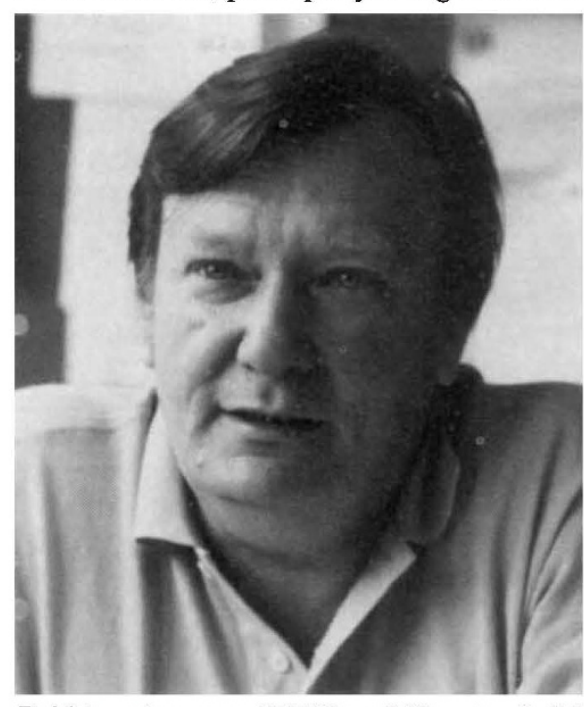

Rubbia stresses CERN's ability to build accelerators.

tium, elsewhere? Rubbia notes that the present machines will have life left in them at the turn of the century, and that diversifying of present interests could also provide continuity on the Geneva site. But that is Rubbia's cautious side. The chances that he will be making a fierce fight for some new machine at Geneva a few years from now.
Small but a powerful membership

\section{London}

THE European Science Foundation (ESF), based in Strasbourg, is the smallest but one of the most interesting of all European collaborations. It has a budget of its own amounting to less than FF14 million a year, but its influence is much greater than its budget would normally command.

The explanation is that ESF's members are neither people nor governments, but public grant-making agencies in European states. From West Germany, for example, both the Max-Planck Gesellschaft and the Deutscheforchungsgemeinschaft (DFG) belong. All five of the British research councils as well as the Royal Society are members. Altogether, there are 50 members from 18 European countries, Finland and Turkey included.

In practice, what this means is that a project which is backed in Strasbourg is likely to win a sympathetic hearing when its advocates later take the hat around asking for substantial funds to supplement whatever seed money that ESF may have provided.

Perhaps the most striking illustration of this successful way of working is the launching of the European Synchrotron Radiation facility, now being built at Grenoble (page 721). The project first surfaced about a decade ago as a recommendation of an ESF committee consisting of accelerator physicists and potential users.

ESF knew the cost would be beyond its scope, but reckoned that it could carry out the diplomacy required to build a consortium of its grant-making members to launch the project, which has now successfully been done.

Another ESF-originated programme is the European Geotraverse, a project for the geophysical investigation of the Earth's crust along a line from Scandinavia to north Africa.

Latterly, ESF has been spending much of its budget on supporting networks of research with funds with which to organize meetings and regular visits among themselves. At the same time, it appears to have accepted that the time has come to grow. ESF's director, economist Michael Posner, is working on a "forward look" that would multiply ESF's budget by three or even five.

The foundation has also appointed a new president to take over from Professor Eugen Seibold, whose term ends in 1990. Professor Umberto Colombo, chairman of Italy's Nuclear Energy Agency, will take over in November 1990. 